\title{
STRESS FRACTURES OF THE FIBULA
}

\author{
A Review of Fifty Cases in Athletes
}

\author{
M. B. Devas and R. Sweetnam, London, England
}

\section{From the Middlesex Hospital}

Stress fractures of the lower part of the fibula are common in athletes. This paper reviews fifty such injuries and discusses the natural history, signs, symptoms, radiographic appearances and treatment. All were seen in the Athletes' Clinic at the Middlesex Hospital between 1952 and 1955, at which they represented an approximate incidence of 3 per cent of new patients seen.

An excellent summary of the literature was given by Burrows (1948), who recorded twenty-four stress fractures of the lowest third or middle third of the fibula, and a larger number in the uppermost third. Since then ten more have been published, eight in children, by Griffiths (1952) and two by Richmond and Shafor (1955). The high incidence in athletes has not been noted before.

\section{CLINICAL MATERIAL}

Table I gives details of the present series. All the fractures were confirmed radiologically. The circumstances in which they occurred have been studied in the thirty-one patients whom

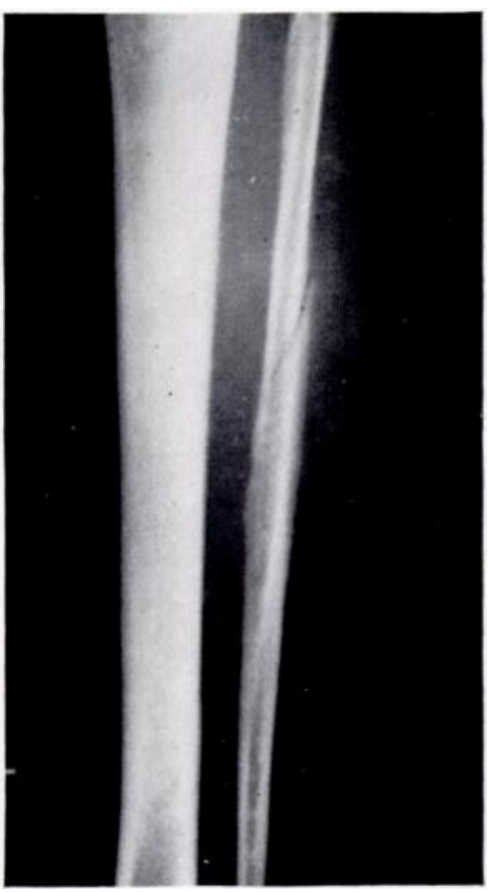

Fig. 1

A marathon runner aged thirty-eight felt a sudden pain in his leg at the twenty-second mile. He had sustained a stress fracture in the mid-shaft of the fibula. The downward and inward direction of the fracture line is unusual. we have been able to follow up. The remainder could not be traced. Five stress fractures of the fibula seen during the same period, but not in athletes, are excluded from the series.

The conditions of sport and state of training were investigated (Table II), and it is apparent that running on hard surfaces was the most common and, we believe, important factor in the etiology.

\section{HISTORY}

The patients usually presented themselves about ten days after the onset of symptoms, but occasionally within twenty-four hours. The onset was abrupt or insidious, and this divided the series quite sharply into two groups (Table III). Those with an abrupt onset experienced severe pain which was felt suddenly above and behind the outer side of the ankle; the patient had no doubt that at one moment he was normal and the next painfully crippled. The oldest man in the series came into this category; he was a marathon runner aged thirty-eight who experienced a sudden acute pain at the end of his twenty-second mile (Fig. 1). An insidious onset was rather more common. There was no particular moment when the symptoms started but a gradually increasing pain became apparent either during or after activity. 
The pain was frequently spoken of as being behind the ankle and the patient located the tender spot well to the back of the fibula. Sometimes a swelling was noticed above the lateral malleolus. Walking was possible with a greater or lesser degree of limp, but running or going upstairs caused pain at the site of the fracture.

TABLE I

Clinical Detalls of Stress Fractures of the Fibula in Athletes (Forty-nine athletes: fifty fractures)

\begin{tabular}{|c|c|c|c|c|c|c|c|}
\hline \multicolumn{2}{|c|}{ Type of sport } & \multicolumn{3}{|c|}{ Sex } & \multicolumn{3}{|c|}{ Site } \\
\hline Running & .46 & Male & . & .46 & Left & . & 26 \\
\hline Football & . 2 & Female & . & 3 & Right & . & 22 \\
\hline \multicolumn{2}{|c|}{ Squash rackets 1} & & & & Bilater & & . 1 \\
\hline
\end{tabular}

TABLE II

Conditions and Training in Thirty-one Athletes with Stress Fractures Seen at Follow-up

\begin{tabular}{|c|c|c|}
\hline \multicolumn{2}{|c|}{ Running on hard roads . } & 16 \\
\hline Running on har & surfaces & 9 \\
\hline Playing football & . & 2 \\
\hline Long jumping* & . & 1 \\
\hline Squash rackets & - & 1 \\
\hline \multicolumn{2}{|c|}{$\begin{array}{l}\text { Running on soft ground . } \\
\text { (One case bilateral) }\end{array}$} & 2 \\
\hline In training & . $\quad 30$ & Usual sport . 29 \\
\hline Out of training & . & Unusual sport \\
\hline
\end{tabular}

* This athlete was normally a middle distance runner.

TABLE III

Mode of Onset of Thirty-one Stress Fractures

$$
\begin{array}{lllll}
\text { Abrupt } & \text {. } & 12 & \text { Insidious . } & 19
\end{array}
$$

\section{DIAGNOSIS}

Stress fractures of the fibula can be recognised without difficulty if the characteristic history and physical signs are appreciated.

Clinical examination always shows an area of tenderness, usually just above the lateral malleolus, and pain is elicited at this site by pressing the fibula towards the tibia. Swelling is present at this level in severe and in late cases, and, although soft and tender at first, it becomes bony hard after a time. The appearance of the swelling is shown in Figures 2 and 3. 


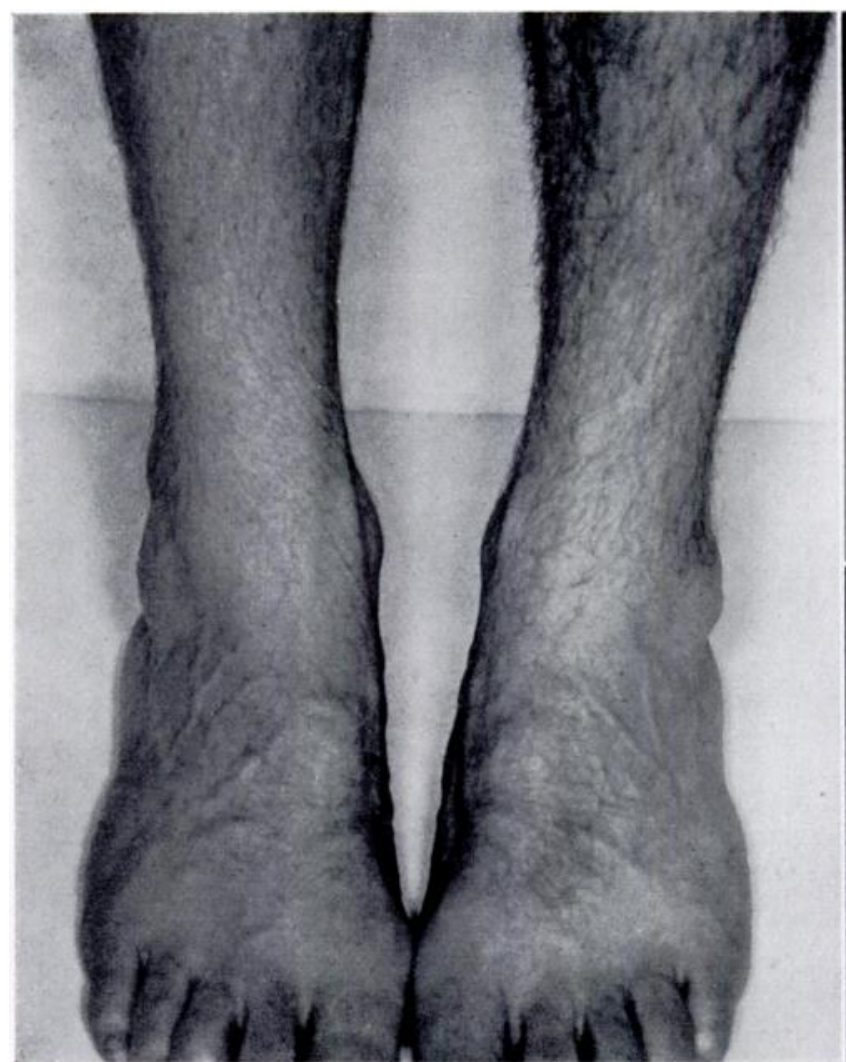

Fig. 2

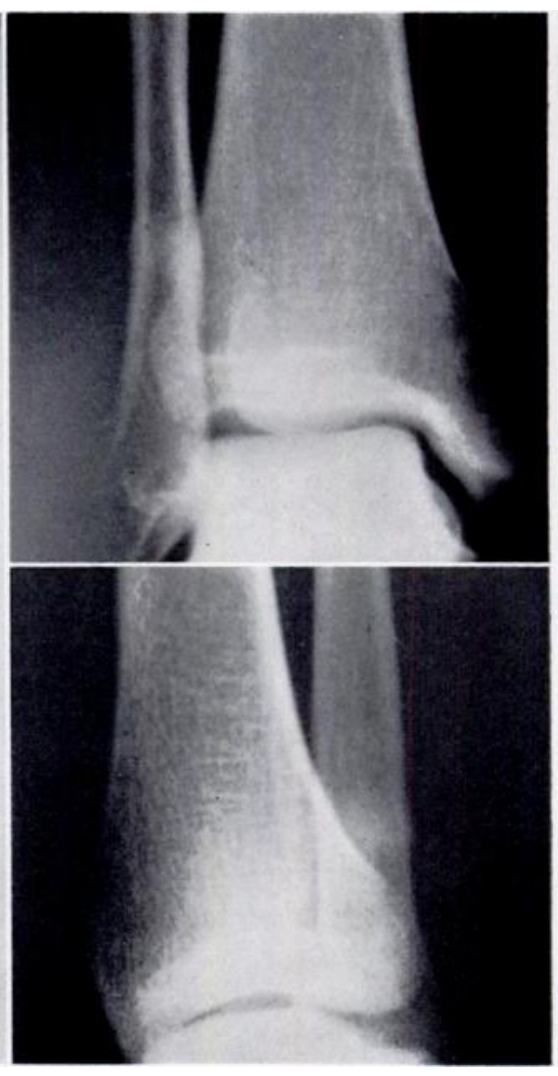

Fig. 3

Figure 2-Only by comparing both ankles with the legs internally rotated can the swelling above the right lateral malleolus be seen with ease. Figure 3-The radiographs show the stress fracture clearly five weeks after the onset of symptoms.

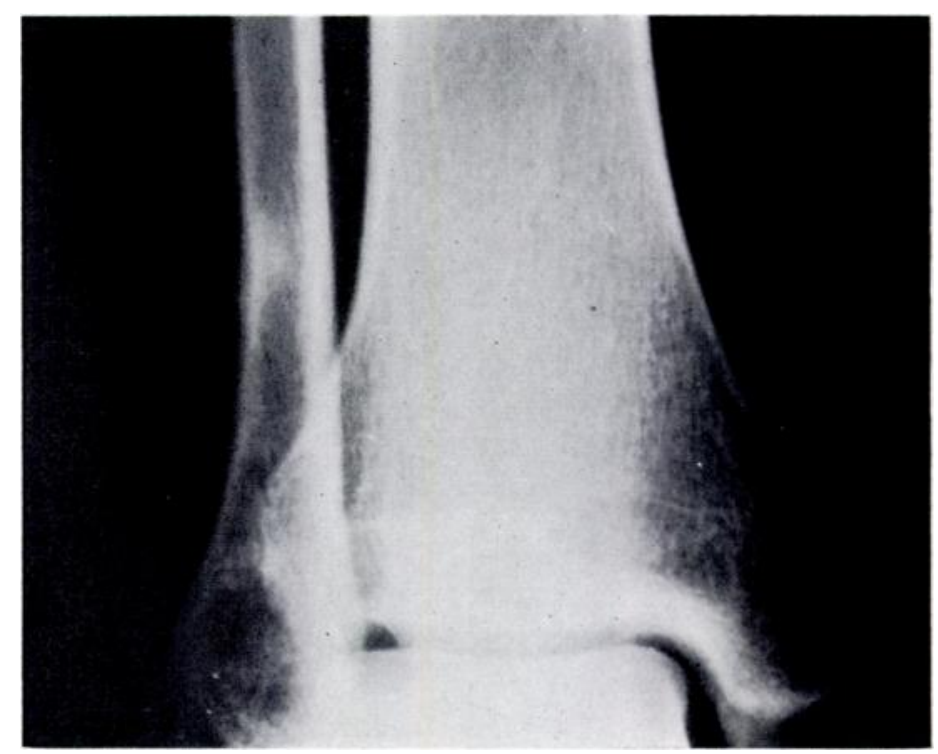

Fig. 4

In a radiograph taken two weeks after the onset of symptoms a slight periosteal reaction could be seen when the film was held to a naked bulb. At four weeks (above) the typical appearances of a stress fracture are seen. 


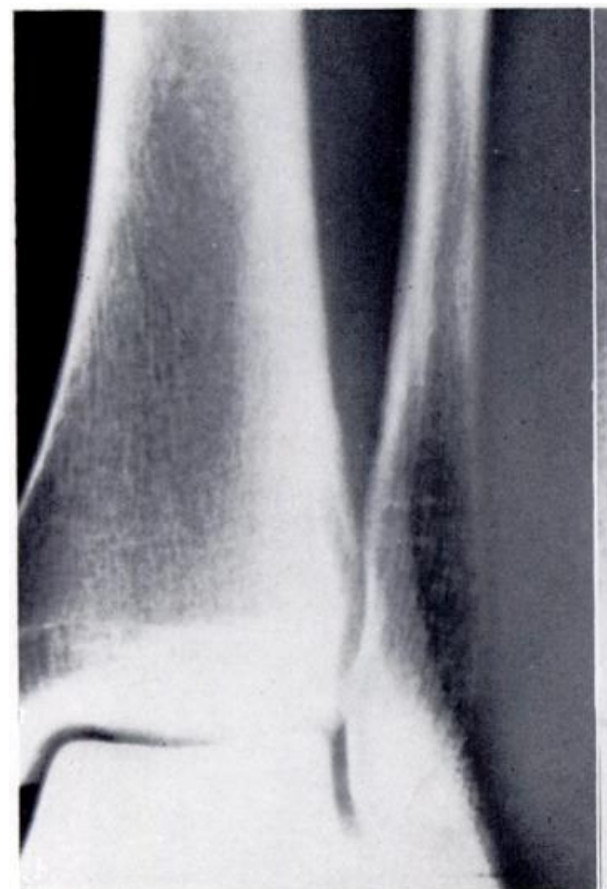

Fig. 5

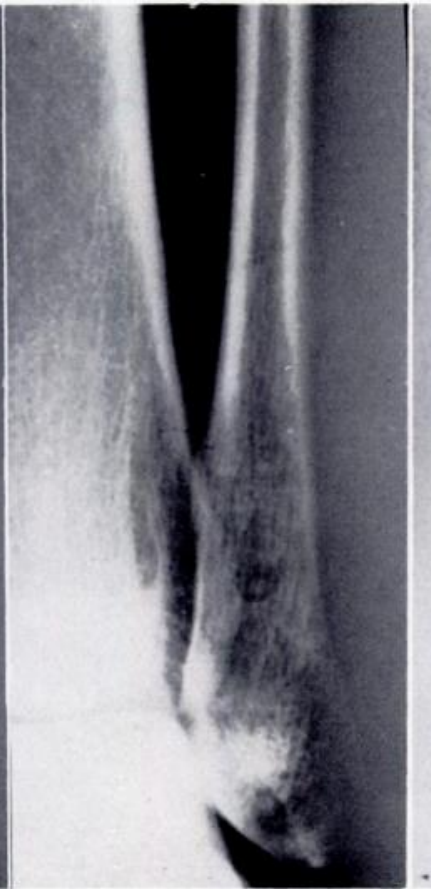

Fig. 6

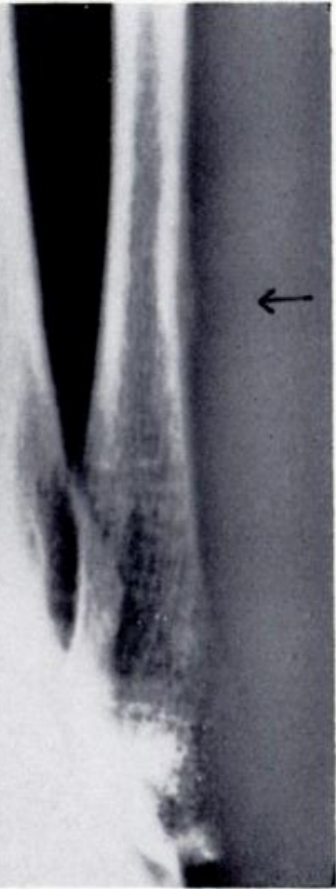

Fig. 7

The radiographic changes of stress fractures of the fibula frequently appear late. In Figure 5 no abnormality is seen ten days after the onset of symptoms, and in Figure 6 at four weeks the changes are slight. At six weeks (Fig. 7) the periosteal new bone and the fracture are seen more clearly.

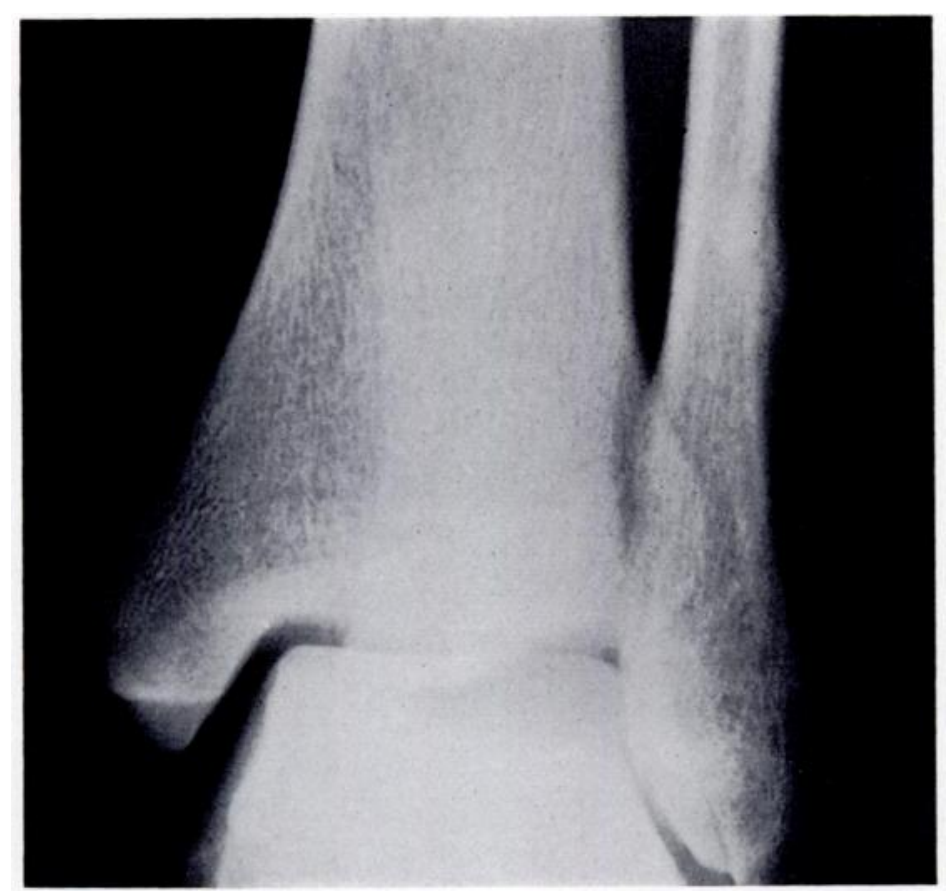

Fig. 8

Nine weeks after this stress fracture occurred the fracture line is clearly visible and callus is consolidating about it.

VOL. 38 B, NO. 4, NOVEMBER 1956 


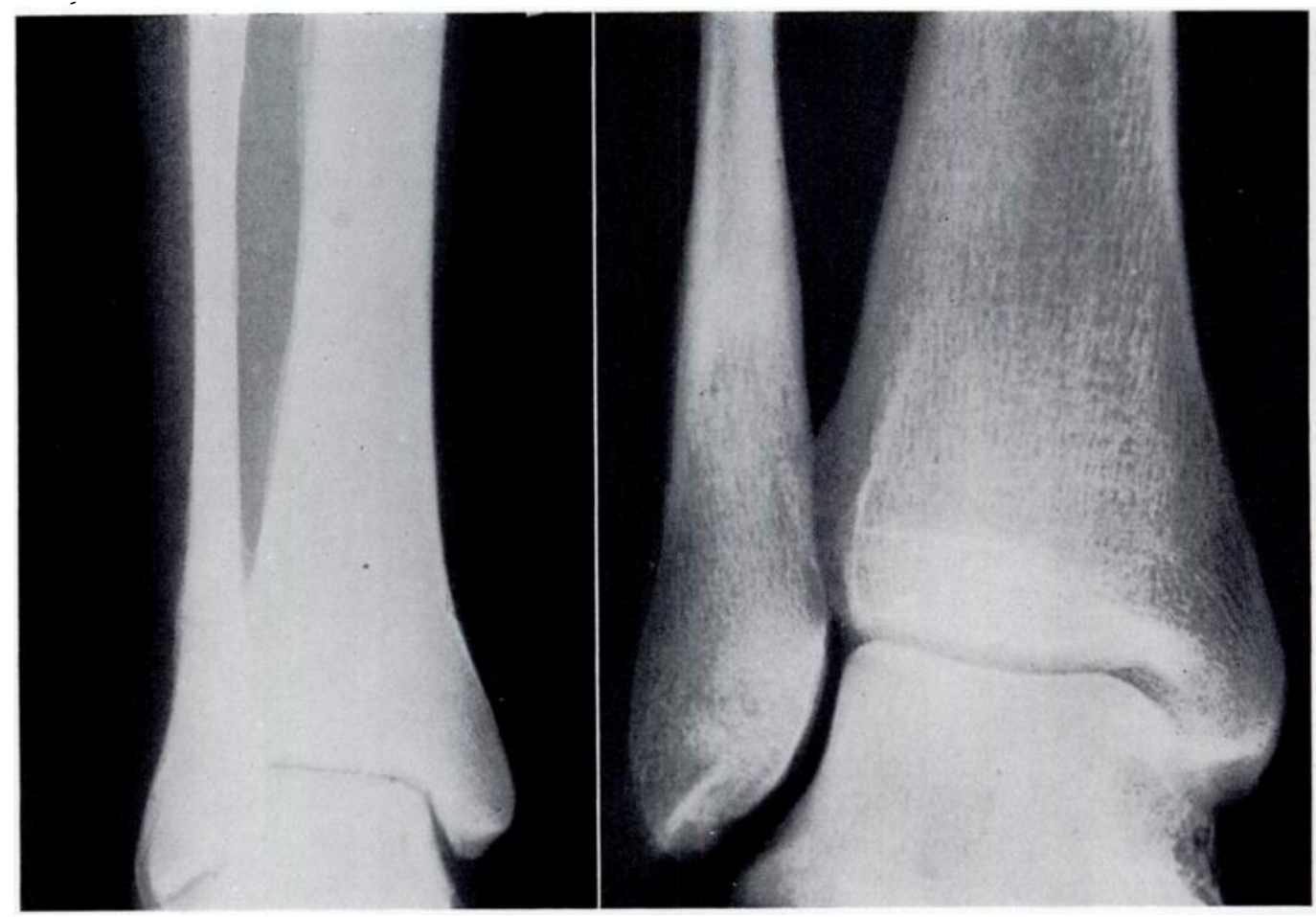

Fig. 9

Fig. 10

Figure 9-This fracture could be seen clearly two weeks after the onset. Figure 10-Three years later buttressing can still be seen at the fracture site.

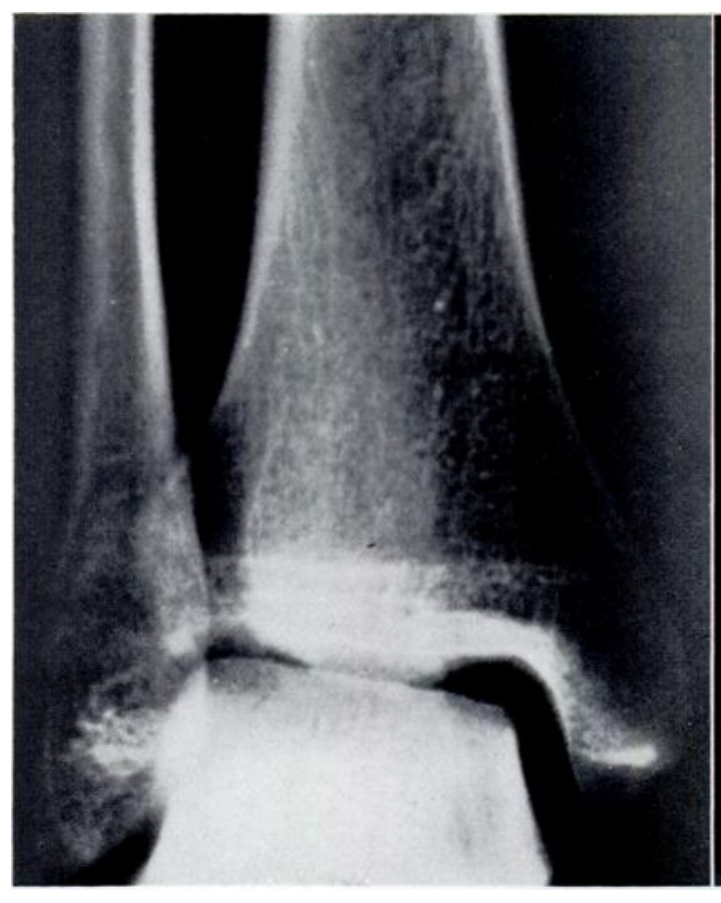

Fig. 11

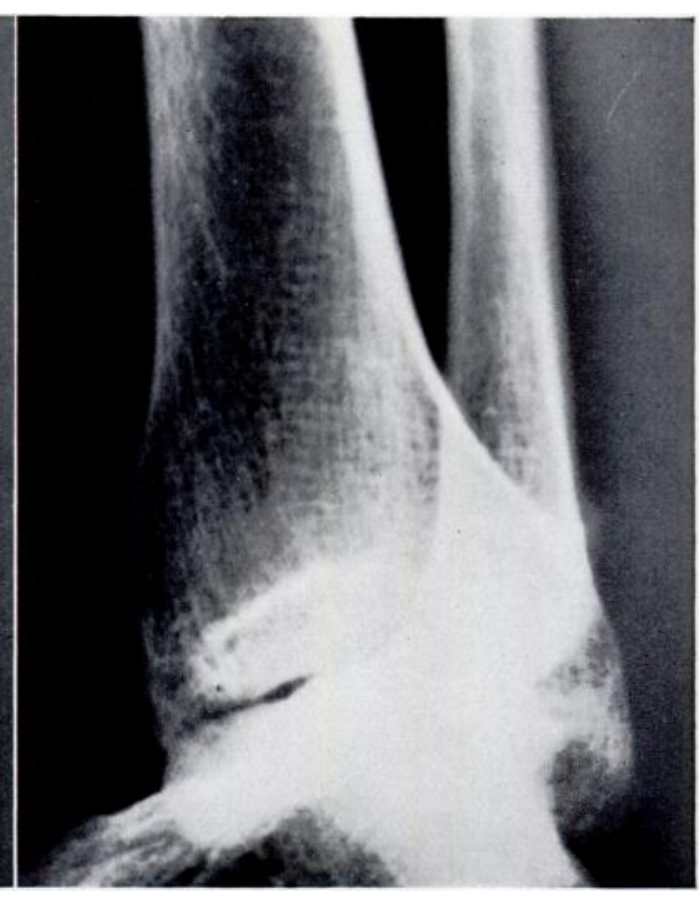

FIG. 12

More than one projection may be required to show a stress fracture. Here the antero-posterior view (Fig. 11) appears normal but an oblique view (Fig. 12) shows a small mass of new bone which confirmed the clinical diagnosis.

THE JOURNAL OF BONE AND JOINT SURGERY 
The two ankles are most easily compared when the legs are rotated a little inwards so that the fibulae are seen in profile.

It is important to realise that radiological changes are late, and often the typical appearance cannot be seen for four weeks (Fig. 4). Figures 5 to 7 show an example in which they were clearly seen only six weeks after the onset of symptoms. In most patients the first change that may be just visible after some two weeks is a hazy patch of new bone on the postero-lateral aspect of the fibula just above the inferior tibio-fibular joint. This thin callus will not be seen unless the film is inspected against a naked bulb, because in routine radiographs

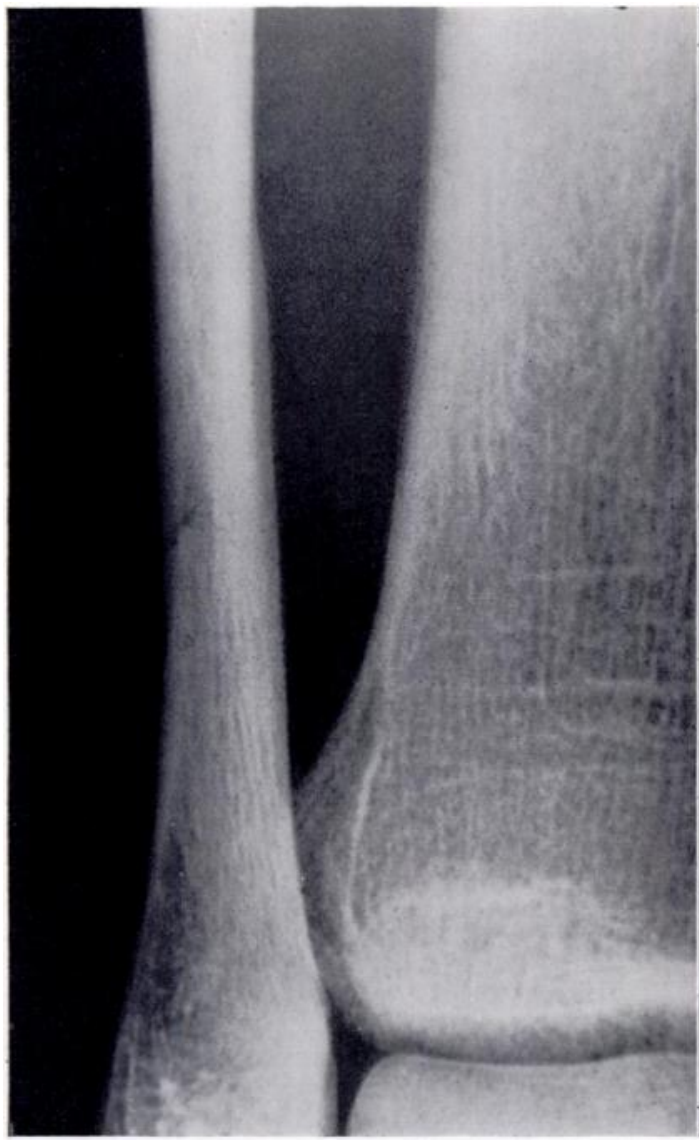

Fig. 13

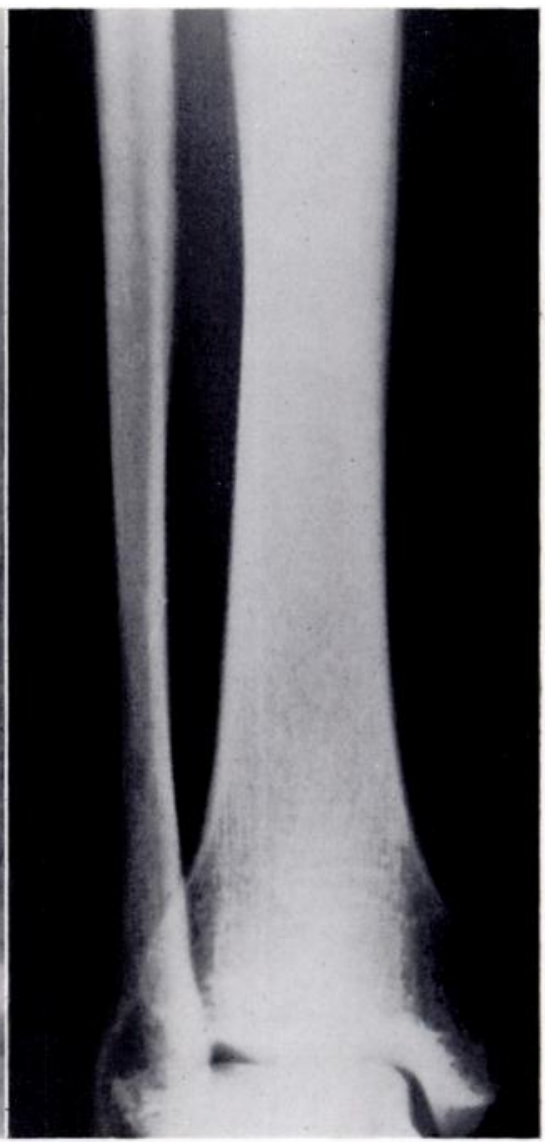

Fig. 14

A macrograph carefully centred (Fig. 13) may show the fracture when normal radiographs do not (Fig. 14). Here both are reproduced in relative sizes.

of the ankle this part of the fibula is, of necessity, "over-exposed." Later, when the callus has consolidated, it is clearly visible and the fracture line may be seen running through the cortex (Fig. 8).

In a few patients the fracture line was clearly seen from the onset, or a few days later, and occasionally there were traces of it many years later (Figs. 9 and 10). Oblique and lateral views may show a fracture not visible in antero-posterior projections (Figs. 11 and 12). In the early stages a " macrograph" carefully centred over the tender area will often reveal the fracture line or a little callus not visible on ordinary non-magnified films (Figs. 13 and 14).

VOL. 38 B, NO. 4, NOVEMBER 1956 
THE LEVEL OF FRACTURE

Stress fractures of the fibula have been classified according to the level, but in this series it was impossible to distinguish between fractures of the lowest third and middle third from the history of the mechanism of injury, and apart from the actual site of the lesion the symptoms and signs were identical. Analysis of forty radiographs in which the level of the fracture could be identified accurately shows an overwhelming preponderance in the lowest third of the bone (Fig. 15).

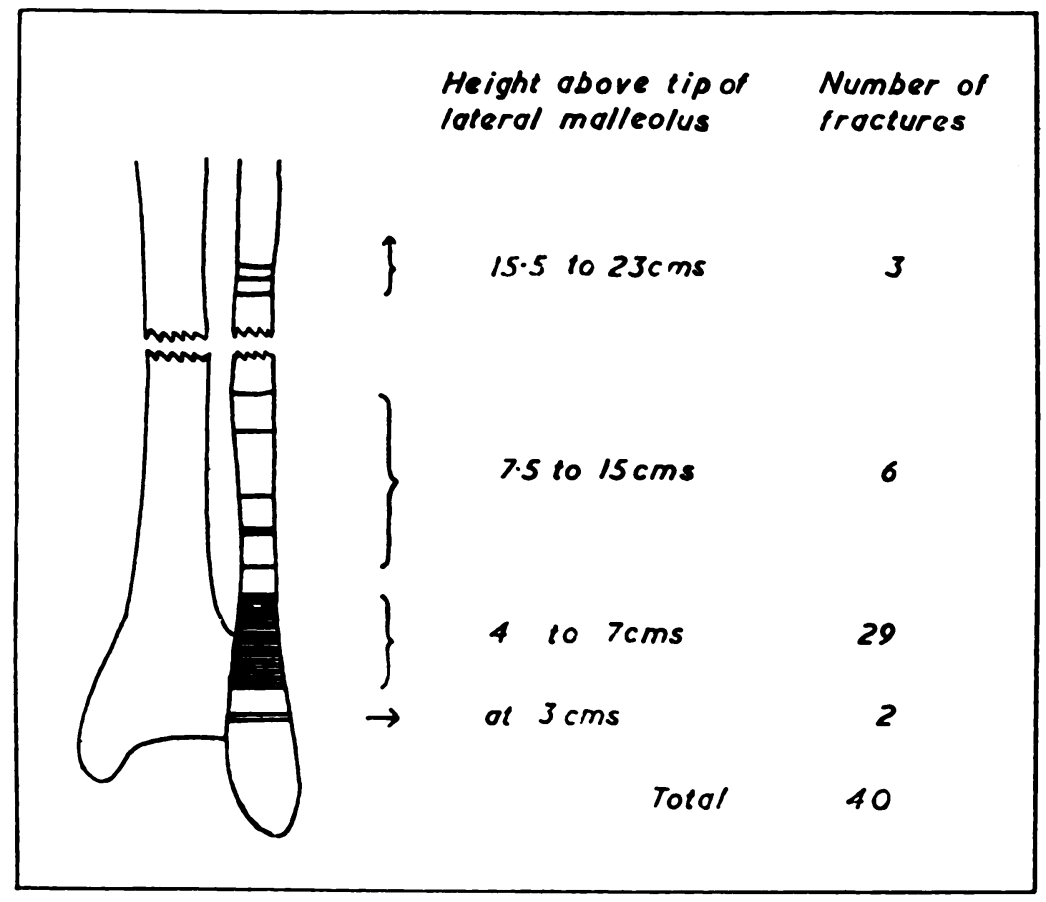

Fig. 15

Level of fracture in forty athletes.

No stress fracture in the uppermost third of the fibula is included in this series but there are many recorded in the literature. Several patients with fractures from muscle violence in this region have been seen but were excluded from this study; the radiographs of one patient with this condition are shown in Figures 16 to 18 . In this instance a careful history showed that the injury occurred from one sudden badly coordinated muscular contraction and not from long-continued and repetitive muscular exertion. None of the athletes with stress fractures gave any indication that an untoward or violent muscular contraction had preceded his symptoms, whether the onset had been insidious or abrupt. The difference between stress fractures and fractures from muscle violence is more than academic, for the latter may be associated with considerable tissue damage, whereas stress fractures are not.

It was noticed in this series that low fractures tended to be transverse and the higher fractures oblique (Figs. 19 to 22). Between these extremes, at the common site, about six centimetres above the lateral malleolus, the obliquity varied. With only one exception (Fig. 1) the fracture line, whatever the level, ran upwards, inwards and forwards. The frequent absence of periosteal reaction on the inner side of the fibula suggests that the fracture was not always complete and did not involve the medial cortex (Figs. 8, 11 and 12, and 21 to 24). The obliquity is well illustrated in the patient with bilateral stress fractures (Figs. 23 and 24) 


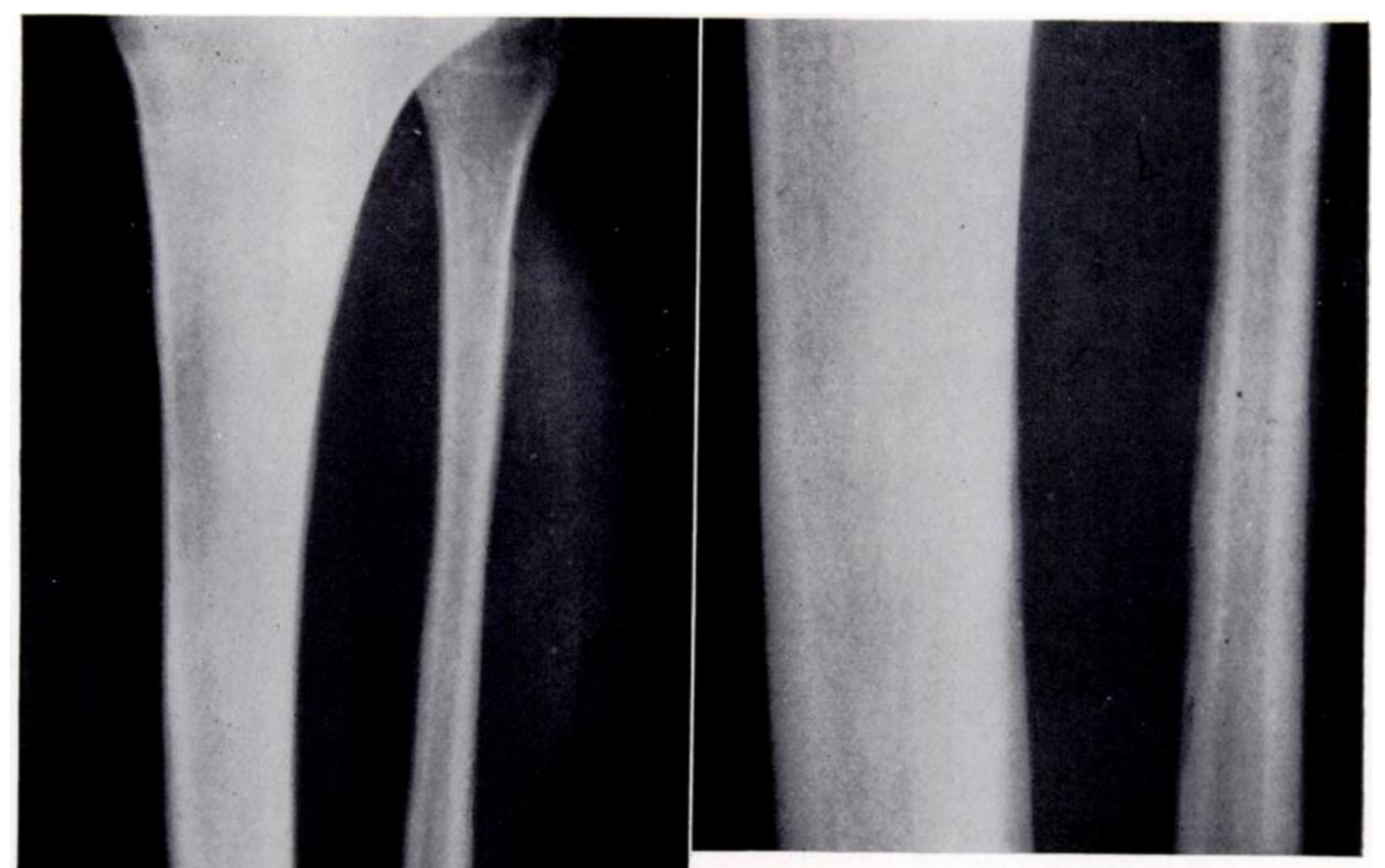

FIG. 17

FIG. 16

With no other injury than making an awkward but violent kick at football the player felt a severe pain in his calf. The initial radiographs showed no abnormality (Fig. 16) but at two and four weeks

the callus and fracture line can be seen (Figs. 17 and 18). This is not a stress fracture but a fracture from muscle violence, and soft-tissue damage may be considerable.

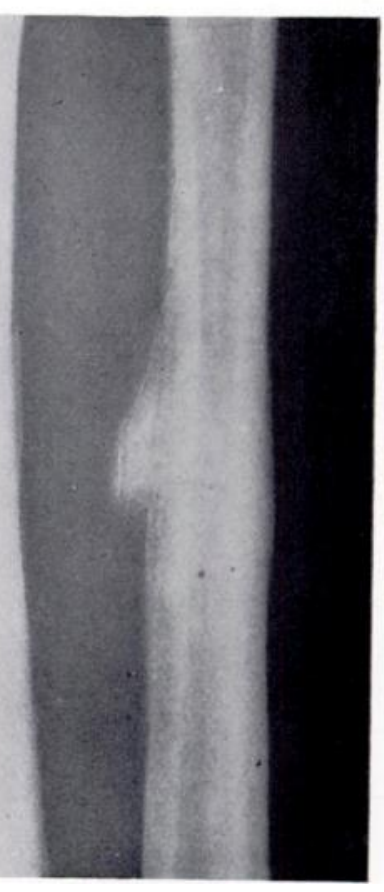

FIG. 18

VOL. 38 B, NO. 4, NOVEMBER 1956 


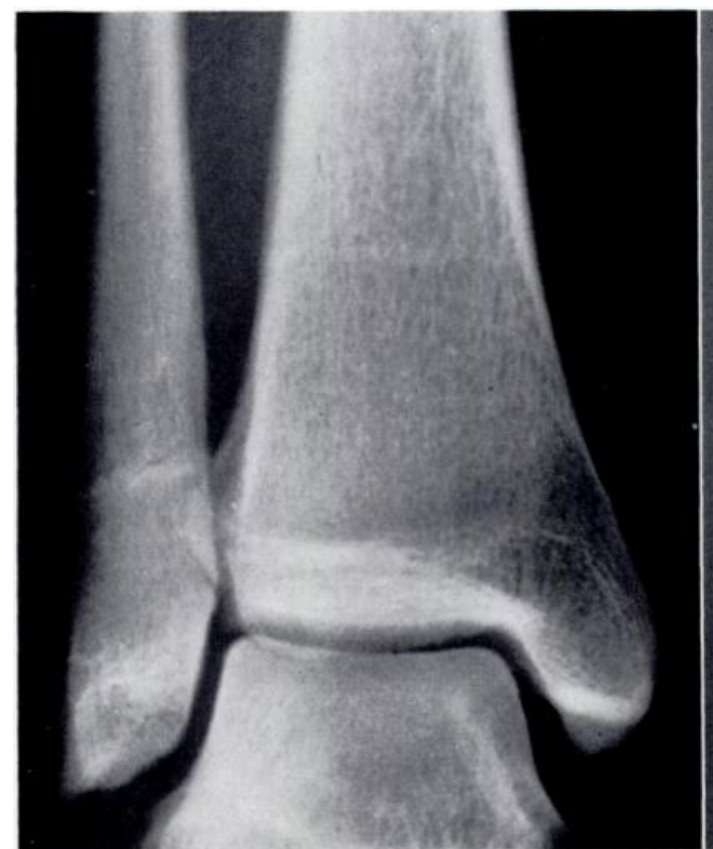

FIG. 19

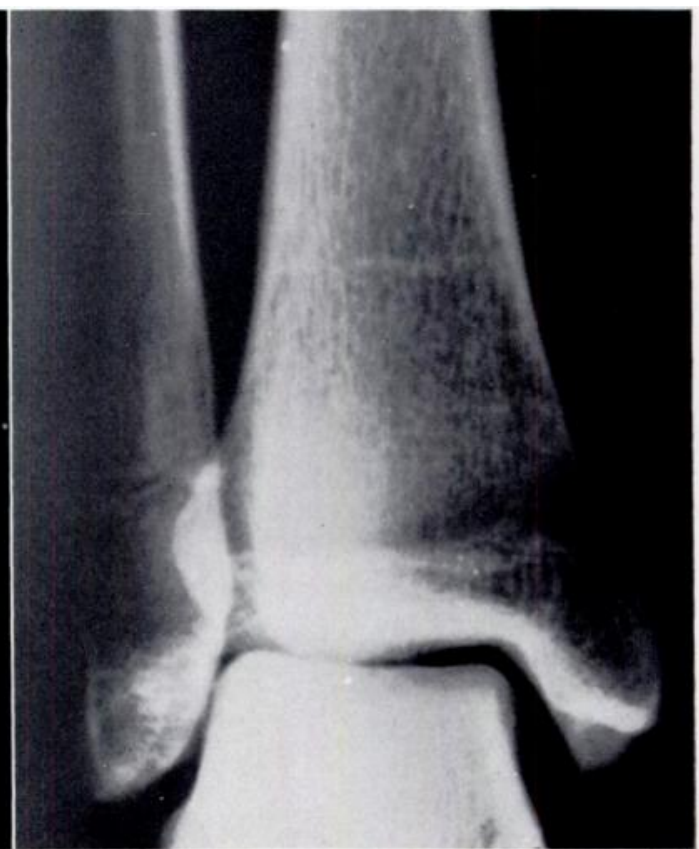

FIG. 20

Figure 19-At one week a fracture line is seen running upwards and inwards. Figure 20 shows the appearance at three weeks: both cortices have been involved. This was among the lowest of the fractures, being $3 \cdot 5$ centimetres from the tip of the malleolus.

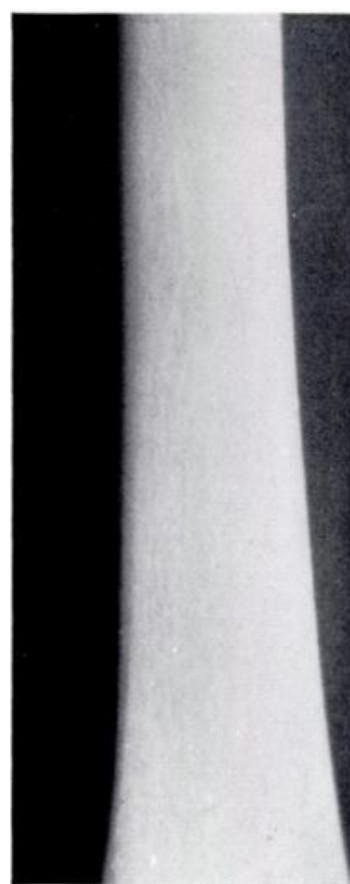

Fig. 21
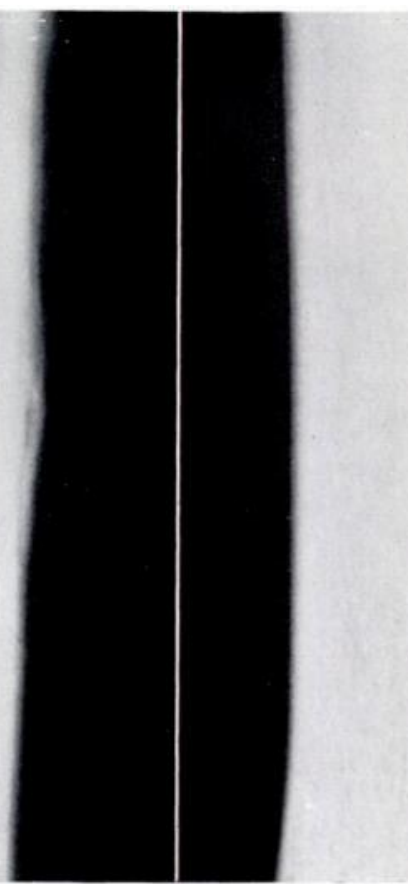

FIG. 22

A high, long, oblique stress fracture running upwards and medially is shown at four weeks (Fig. 21) and at twelve weeks (Fig. 22). There is nothing to suggest that the medial cortex of the fibula has been involved. 
which occurred within a week of each other. He had attempted to continue running with the painful ankle strapped, only to sustain a similar injury on the opposite site.

\section{MECHANISM}

We have shown (Table II) that stress fractures of the fibula in athletes occur most commonly from running on hard surfaces. On hard ground a runner tends to land " on his

TABLE IV

Seasonal Incidence of Stress Fractures in Fifty Athletes

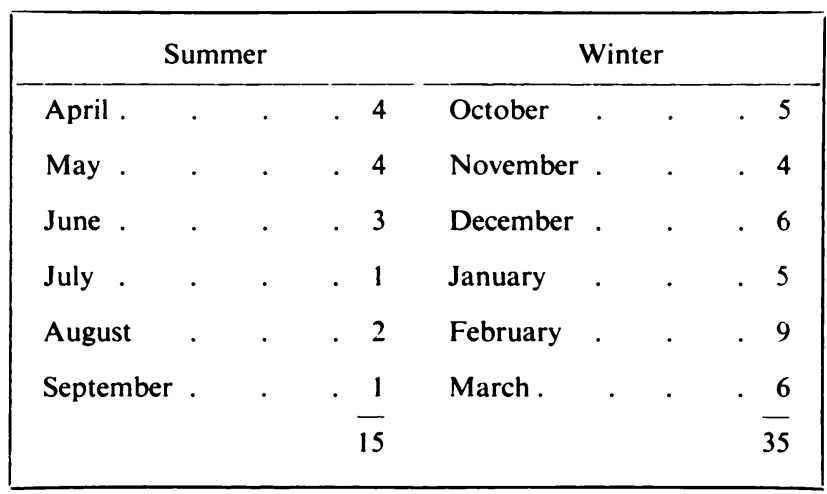

toes" to protect himself from the jar of each footfall, whereas on a soft track or grass the weight is better distributed over the foot. This may explain the high seasonal incidence in the winter months (Table IV) when road running as a form of training is most common.

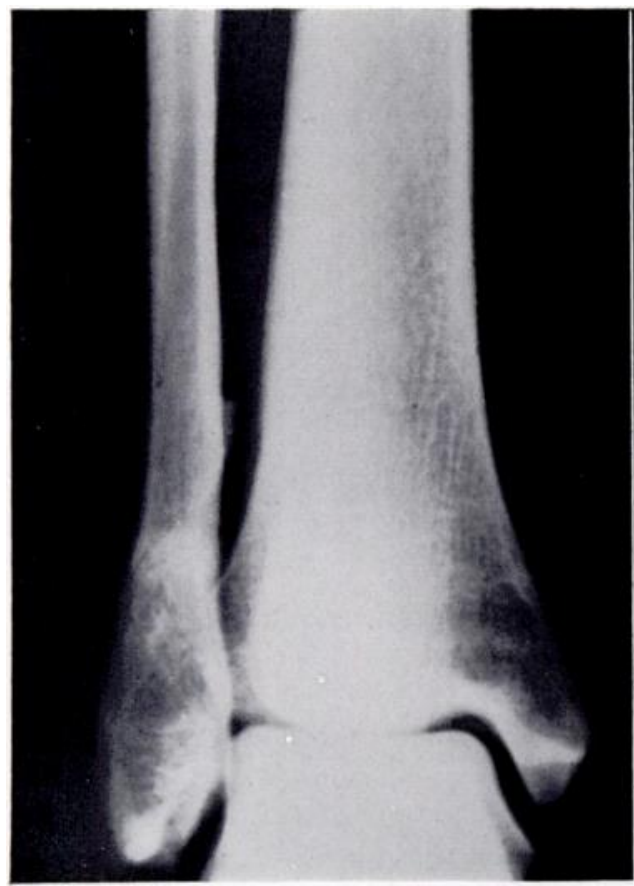

Fig. 23

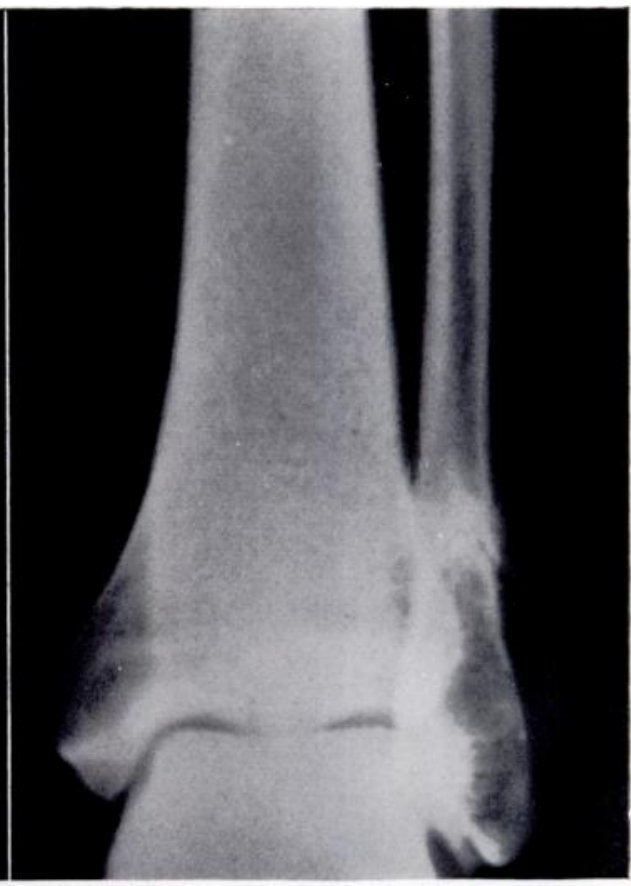

FIG. 24

When one ankle became painful an athlete tried to " run it off" with a result that both fibulae had stress fractures. The upward and medial direction of the fracture line, which involves both lateral and medial cortices, is shown well.

Vol. 38 B, NO. 4, NOVEMBER 1956 
It could be that the strong recurrent and rhythmical contraction of the plantar and long toe flexors transmits, through their origin from the fibula, the extra stress that produces the fracture. To discover the effect of this muscle pull on the fibula, radiographs were taken of the legs of healthy subjects, first with the foot resting, and secondly while they were exerting a strong downward thrust through the ball of the foot. Movement of the leg and foot was prevented by holding them in a wooden frame (Fig. 25).

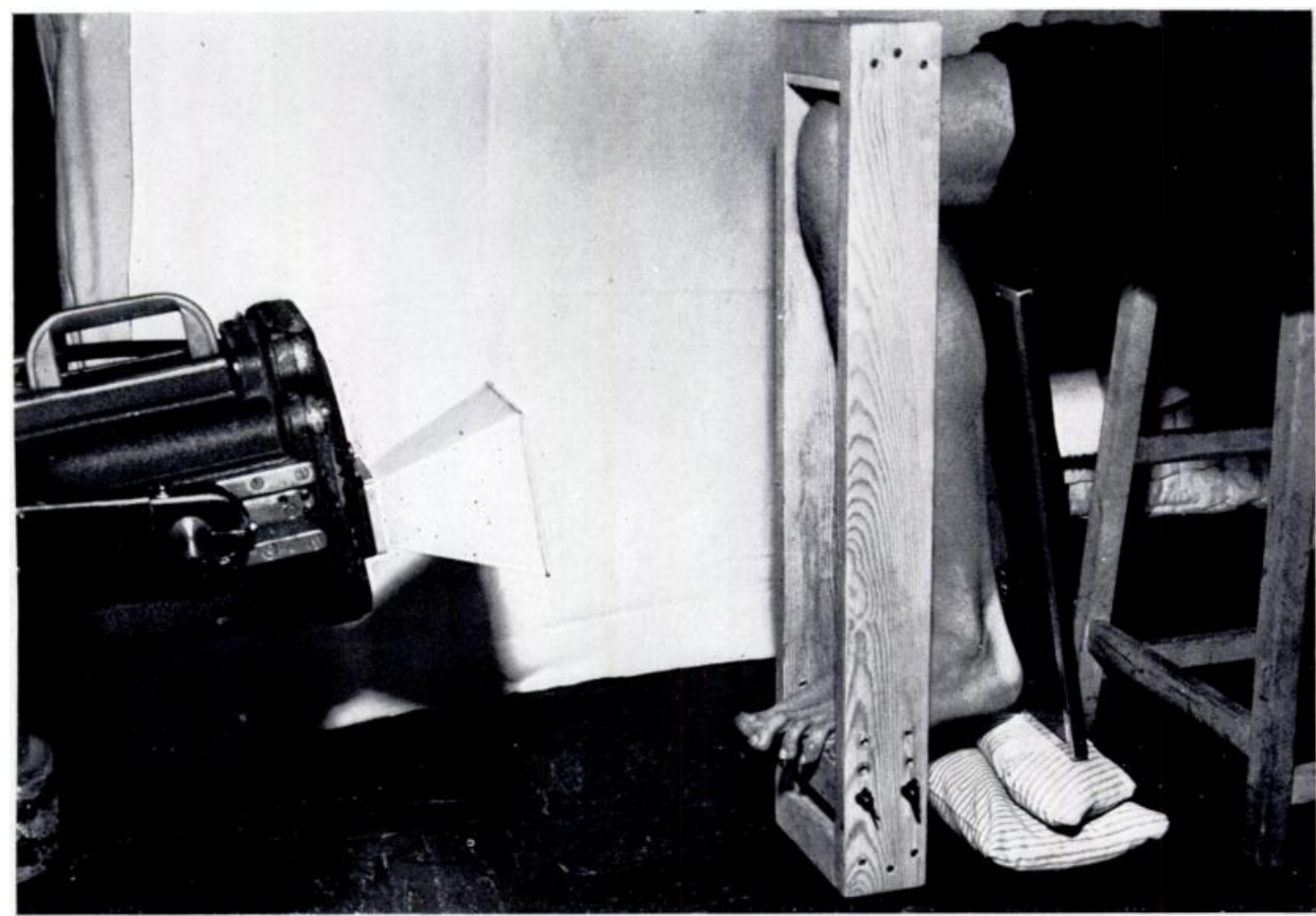

Fig. 25

By means of a wooden frame adjustable for different leg lengths, radiographs of normal legs were taken with the calf muscles first at rest and then exerting a strong downward thrust. The radiographs were superimposed to show any alteration in the relative positions of the tibia and fibula.

Comparison of the radiographs shows that powerful contraction of the flexor muscles approximates the fibula to the tibia. When these films are superimposed with the tibial shadows corresponding exactly, the altered position of the shaft of the fibula is clearly seen (Fig. 26). It is suggested that in running on the toes there is a "to-and-fro" movement of the fibula, the point of greatest stress being near the inferior tibio-fibular joint, and this is the most frequent site for a stress fracture.

\section{TREATMENT}

Without treatment, pain and disability usually continue for three to six months and the athlete who tries to continue training without a period of rest will lose a whole season. With suitable treatment we have found six weeks to be the average time away from athletic activities. Immediate rest from sport is essential; the all too common advice of the trainer to " run it off" results in continued pain, longer incapacity and marked radiographic changes. 
Adhesive elastic strapping is applied from the metatarsal heads to below the knee and normal walking is allowed; there is no reason for being off work. This regimen is continued until there is no longer any tenderness on firm pressure over the previously tender area, or pain on compression of the fibula towards the tibia-usually about six weeks from the onset of symptoms. Only then is the strapping discarded and gentle training on a soft surface resumed.

Provided there is no return of symptoms, activity is gradually increased during two or three weeks until the athlete is back to his normal training programme, but running on roads is forbidden.

Other methods of treatment have been tried but found less satisfactory. Both below-knee walking plasters and the continuation of sport, in supportive strapping, aggravated the symptoms and prolonged the disability. There is some indication that thick rubber-soled running shoes reduce the intensity of pain but although it may be a useful prophylactic measure it has not been recommended as a form of treatment.

FIG. 26

Superimposed radiographs of a normal leg taken in the manner shown in Figure 25. The tibia and lateral malleolus fit exactly, but there is an obvious double shadow of the shaft of the fibula. A powerful contraction of the flexor muscles of the calf has approximated the fibula to the tibia.

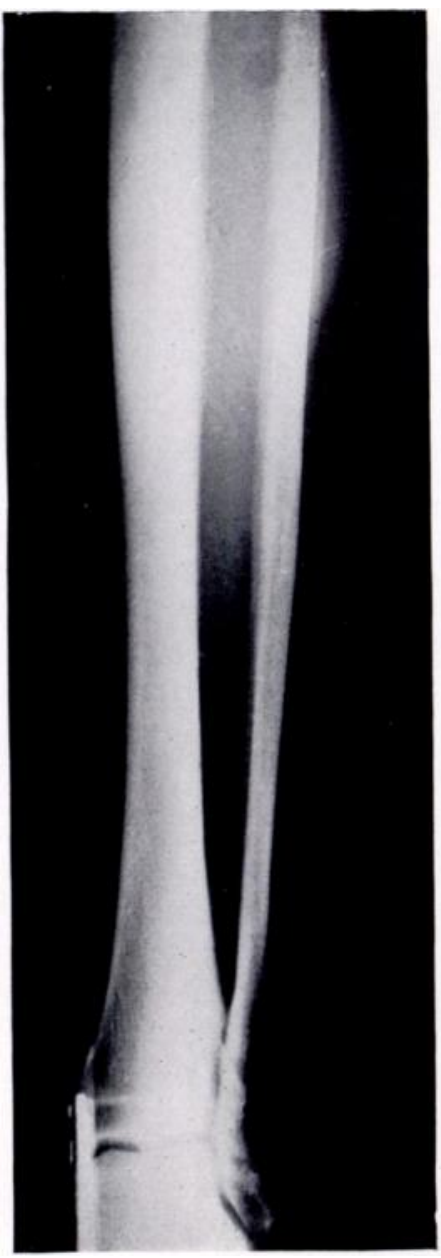

FIG. 26

\section{SUMMARY}

1. An account is given of fifty stress fractures of the fibula which occurred in athletes.

2. The characteristic symptoms, signs and radiological appearances are described, with details of treatment and prognosis.

3. The mechanism of the injury has been suggested on clinical grounds and supported by experimental methods.

We would like to express our gratitude to Mr Philip Wiles and $\mathrm{Mr} \mathrm{P}$. H. Newman for their advice and encouragement in both the clinical investigations and the preparation of this report. We also wish to thank $\mathrm{Mr}$ M. Turney and other members of the Photographic Department of the Middlesex Hospital for the photographs.

\section{REFERENCES}

Burrows, H. J. (1948): Fatigue Fractures of the Fibula. Journal of Bone and Joint Surgery, 30-B, 266.

Griffiths, A. L. (1952): Stress Fractures of the Fibula in Childhood. Archives of Diseases of Childhood, 27, 552. Richmond, D. A., and Shafor, J. (1955): A Case of Bilateral Fatigue Fractures of the Fibula. British Medical Journal, i, 264. 